\title{
The Porosity and Wettability Properties of Hydrogen Ion Treated Polytetrafluoroethylene
}

Hernando S. Salapare III*, Gene Q. Blantocas, Virginia R. Noguera, and Henry J. Ramos Plasma Physics Laboratory, National Institute of Physics, University of the Philippines, Diliman, Quezon City 1101, Philippines

Telefax: +63-2-9204475, +63-2-9280296

*Corresponding author: hsalapare@nip.upd.edu.ph

\begin{abstract}
The porosity and wettability properties of hydrogen ion treated polytetrafluoroethylene (PTFE) materials are related using contact angle, scanning electron microscopy (SEM), and ellipsometry tests. PTFE are irradiated using a low energy hydrogen ion shower (LEHIS) produced by a Gas Discharge Ion Source (GDIS). The plasma discharge current $\left(I_{d}\right)$ is varied at intervals of $1 \mathrm{~mA}$. Results show that treatment using lower $I_{d}$ enhances the hydrophobic property of the PTFE material with contact angle value of as high as $118.6^{\circ}$. It also becomes less porous as indicated by the increase in the index of refraction, decrease in optical transmittance, and increased scissions and striations in the SEM images. Opposite effects are observed for higher $I_{d}$.
\end{abstract}

PACS CODES: 81.65.-b, 68.35.bm, 61.80.-x, 68.08.Bc, 07.60.Fs 
KEYWORDS: Polytetrafluoroethylene (PTFE), porosity, low energy hydrogen ion shower (LEHIS), gas discharge ion source (GDIS), wettability, contact angle, ellipsometry, scanning electron microscopy (SEM).

\section{INTRODUCTION}

Surface modification of polymer materials has been of great interest in most researches for the past years because of its importance in the field of materials science, electronics and biomedical physics. Surface modification technology allows for the change and improvement of the property of a material, consequently making the processed material more useful in various aspects [1-4]. Different characterization techniques that determine the change in the surface of the material include X-ray photoelectron spectroscopy and atomic force microscopy, which provide surface profiles of the polymers [5-6]. Other characterization techniques involve ellipsometry and flourophotometry in which the dielectric function and structure of the material could be obtained [7]. The most common technique to assess the surface modification of a material is through contact angle measurements.

Modified porosity and wettability surfaces of polymer materials find usefulness in orthopedic science [8], tissue engineering [9], immobilization of lipase [10-13], cell culture [14], and drug delivery [14].

The material being modified in this study is a polytetrafluoroethylene (PTFE) commonly known as Teflon. It is the chosen material because it is the simplest organic polymer that is analogous to polyethylene. Changing the wettability of PTFE is of great 
importance because of its applications in biosensors, hemo-compatible materials, immobilized enzymes, MEMS, and electronics [15-22]. PTFE materials' wettability is changed to either hydrophilic or hydrophobic depending on its intended application [23].

In this study, PTFE materials are treated using a low energy hydrogen ion shower (LEHIS) system. The effect of the treatment on the porosity and wettability of the material is investigated using contact angle measurements, scanning electron microscopy (SEM), and ellipsometry tests.

\section{METHODOLOGY}

\subsection{Experimental Device and Procedures}

The PTFE tape of size $1 \mathrm{~cm} \times 2 \mathrm{~cm}$ is wrapped around a $2 \times 2 \mathrm{~cm}^{2}$ stainless steel plate holder. The surface of the clean samples was blown-dried to prevent the formation of moisture on the surface. It is not subjected to ultrasonic cleaning because of the fragile condition of the samples. PTFE are then irradiated using a low energy hydrogen ion shower (LEHIS) of a gas discharge ion source (GDIS) system. Figure 1(a) shows the schematic diagram of the experimental set-up and figure 1 (b) shows the schematic diagram of the GDIS. It has a compact discharge region of volume of $0.8 \mathrm{~cm}^{3}$ and an exit aperture of $2.0 \mathrm{~mm}$ in diameter. The extraction and focusing electrodes are grounded to ensure a diffused ion shower configuration. The GDIS fits a standard $70 \mathrm{~mm}$ knife-edge flange coupled to the diagnostic chamber whose volume is about $2400 \mathrm{~cm}^{3}$. A $10.16 \mathrm{~cm}$ oil diffusion pump coupled to an $8 \mathrm{~m}^{3} / \mathrm{h}$ rotary pump evacuates the system. Complete details of the facility and its operation are described in references [1-2] and [24-25]. 
Pirani and ionization gauges monitor the pressure inside the chamber. The base pressure is $\sim 1.0 \times 10^{-6}$ Torr. The total hydrogen gas filling pressure is kept at 3 mTorr for all the experimental runs. Plasma is produced when a potential difference, $\mathrm{V}_{\mathrm{d}}$, is applied across the discharge region. The PTFE samples are placed on a holder positioned $70 \mathrm{~mm}$ downstream from the entrance port of the processing chamber. This is the position determined to give maximum ion current density [1]. The irradiation time is set to 30 minutes. Treatment conditions are summarized in Table 1.

\subsection{Characterizations}

\subsubsection{Ion Beam Detection}

The ion species are determined using a cast steel mass spectrometer. The mass spectrometer is then replaced by a Faraday cup system, which consists of an isolated brass disk of $2.0 \mathrm{~cm}$ diameter and is connected to an electrometer. The Faraday cup is used to determine the total ion current density [24].

\subsubsection{Contact Angle Measurements}

The treated and untreated samples are subjected to contact angle test using an Intel ${ }^{\circledR}$ Play ${ }^{\mathrm{TM}}$ QX3 ${ }^{\mathrm{TM}}$ Computer Microscope. The absorption of the water droplet on the sample is recorded at one frame per 5 seconds.

The video of the absorption of water is processed using AVS DVD Media Player to get the images of the absorption every 5 seconds. Image $\mathrm{J}$ is used to measure the contact angle of each frame of the absorption of deionized water. Contact angle is then plotted against absorption time to show the dynamics of the water droplet on the surface of the sample. Three replicates for each experimental condition are considered. 


\subsubsection{Ellipsometry Characterization}

A VASE M-44 ellipsometer (J. A. Woolam Co.) is used to determine the transmission of light through the sample and index of refraction. The transmittance and the index of refraction are considered at 594nm wavelength. This is done to compare the result of the optical transmittance with a previous study [1].

\subsubsection{Scanning Electron Microscopy}

The substrates are coated with gold using a Jeol (JFC-1100) Fine Coat Ion Sputter to avoid the accumulation of electrons on the surface of the material because of its fragile state and because the sample is a non-conducting polymer. A Leica S440 Scanning Electron Microscope (SEM) is used to determine the structure of the surface of the material.

\section{RESULTS AND DISCUSSION}

\subsection{Ion Beam Characterization}

The typical hydrogen ion peaks detected by the cast steel mass spectrometer is shown in figure 2(a). The ion intensities (nA) of the hydrogen beam are plotted against the scanning magnetic field (G). Figure 2(b) shows the ion flux density for different discharge conditions registering a high of $0.25 \mathrm{~A} / \mathrm{m}^{2}$ and a low of $0.06 \mathrm{~A} / \mathrm{m}^{2}$. Monatomic $\mathrm{H}^{+}$ions dominate the $\mathrm{H}_{2}^{+}$ions of the beam produced by the gas discharge ion source for discharge currents of $1 \mathrm{~mA}, 2 \mathrm{~mA}$, and $3 \mathrm{~mA}$. Hence, there is reason to believe that the monatomic ions play an active role in the surface modification process. 


\subsection{Contact Angle Measurement}

Temporal recessions of the contact angles for some representative samples are shown in Figure 3. Wettability is quantified by fitting the wetting dynamics model used in [1, 24] to actual data. The model is expressed mathematically as

$$
\frac{d \theta}{d t}=-k \theta
$$

where $\theta$ is the contact angle between the supporting solid surface and the tangent to the drop-shape of the liquid, and $k$ being the change rate constant or the quantity that describes the angle's temporal recession in units of per second [1]. The increase in the value of $k$ signifies increasing surface wettability. Using the R-squared method it shows that the experimental data is in correlation with the wetting model as indicated by the high values of $\mathrm{R}^{2}$ for all experimental conditions. Samples from the control group and samples from group 1 shows lower values of $k$ which indicates that samples treated using low discharge current are hydrophobic samples. Samples from groups 2 and 3 show higher values of $k$; this indicates that samples treated at higher discharge currents become hydrophilic. Wettability properties are determined by the initial contact angle $(\alpha)$. The $90^{\circ}$ angle separates the hydrophilic and hydrophobic zones [26]. Wetting occurs at $\alpha<$ $90^{\circ}$ and non-wetting if $\alpha>90^{\circ}$.

The cause for the increased hydrophilicity of the samples can be attributed to the increased surface roughness [27-30] and porosity of the material. Hydrophobication by ion irradiation is not yet understood and further experiments are being conducted to explain the phenomena. This result is in correlation with the work of Blantocas, et.al. on the ion irradiation of wood samples [31]. 


\subsection{Ellipsometry Test}

Table 2 summarizes the result obtained from the ellipsometry test. It shows the optical transmittance and the index of refraction of the sample at $594 \mathrm{~nm}$ wavelength.

The optical transmittance investigates material porosity by measuring the transmittance of light through the samples. Transmittance may be regarded as porosity indices of the samples. A porous material tends to have a high transmittance value and at the same time is also likely to have higher water-absorbency. In this sense, transmittance may be regarded as an indicator of material wettability. In Table 2, samples irradiated by low energy ion showers $\left(I_{d}=1 \mathrm{~mA}\right)$ exhibit the least transmittance meaning the material is also the least porous. Samples from group 1 give the lowest transmittance of $69.12 \%$, and also the least wettable having the lowest $\mathrm{k}$ value. The opposite effect is seen for samples irradiated by higher energy beams. Samples from group 3 have the highest transmittance of $98.34 \%$ and the most wettable as well.

The index of refraction of samples treated with low discharge current is higher than those of the index of refraction of samples treated with high discharge current for the 594 nm wavelength. High index of refraction indicates that the density of the material is also high [31]. This would imply that the samples treated with low discharge current has a low density as compared with samples treated with high discharge current.

\subsection{SEM Characterization}

Figure 4 shows the SEM images of the untreated and treated samples. All the SEM images are observed at 20k x magnifications. Figure 4(a) shows the surface of samples from group 1 subjected to lower energy ion showers $\left(I_{d}=1 \mathrm{~mA}\right)$ that are much smoother 
than the rest of the specimens. Samples from group 3 and 4 subjected to higher energy ion showers $\left(\mathrm{I}_{\mathrm{d}} \geq 2 \mathrm{~mA}, 3 \mathrm{~mA}\right)$ shows surfaces that are rough and have striations and scissions as seen in figures 4(c) and 4(d). The surface deterioration of group 3 looks more pervasive than that of sample 2 possibly due higher discharge current. It becomes clear from the figure vis-à-vis wettability and porosity parameters that, generally a surface becomes more wettable and optically transmissive as it roughens. Roughening by high energy ion irradiation leads to surfaces becoming more hydrophilic and porous. The observed striations and scissions on the surface account for their higher optical transmittances. This finding is in consonance with the work of Tzeng et al. on the roughening of Teflon samples using wet processes [28]. Conversely, low energy ion irradiation results in relatively smooth, hydrophobic surfaces. PTFE materials become thinner when bombarded by higher flux density ion showers [1]. Porosity can also be analyzed in relation with the thickness of the material. The optical transmittance in $\%$ as described by the Beer-Lambert law is

$$
\mathrm{T}=\mathrm{P} / \mathrm{P}_{0}=\mathrm{e}^{-\varepsilon b c}
$$

where $\mathrm{P}_{\mathrm{o}}$ and $\mathrm{P}$ are the power of the incident and transmitted light, respectively, $\varepsilon$ is the molar absorptivity of the absorber, $\mathrm{b}$ is the path length of the sample which is also the thickness, and $\mathrm{c}$ is the concentration of the absorbing species in the material. Thinner samples results in higher transmission of light. Cross-sectional SEM images of the samples are reported in [1]. The density and the index of refraction of the material changed due to the air gaps created by the striations as seen from the SEM images. The produced striations and scissions indicate that the material becomes more porous when irradiated by higher energy ion showers. 


\section{CONCLUSIONS}

The porosity and wettability properties of hydrogen ion treated PTFE materials were evaluated using contact angle, ellipsometry and SEM tests. Low discharge LEHIS treatment produces hydrophobic, smooth, less porous surfaces while high discharge LEHIS produces hydrophilic, rough, optically transmissive, more porous surfaces.

\section{ACKNOWLEDGMENTS}

The financial support of the project from the Department of Science and Technology (DOST) - Philippine Council for Advanced Science and Technology Research and Development (PCASTRD) is gratefully acknowledged.

\section{REFERENCES}

[1] H.S. Salapare III, G. Q. Blantocas, V.R. Noguera, and H.J. Ramos, " Low energy hydrogen ion shower (LEHIS) treatment of polytetrafluoroethylene (PTFE) materials", Applied Surface Science (2008) doi:10.1016/j.apsusc.2008.08.079.

[2] H.J. Ramos, J. L. C. Monasterial, G. Q. Blantocas, Nucl. Instru. and Meth. in Phys. Res. B 242 (2006) 41-44.

[3] M. S. Sheu, D. M.Hudson, I. H. Loh, The Encyclopedic Handbook of Biomaterials and Bio-engineering: Part A; Marcel Dekker, New York, 1 (1995) 865.

[4] C. M. Chan, T. M. Ko, Surf Sci Rep (24) (1996) 1.

[5] P.G. de Gennes, Rev. of Mod. Phys. 57 (3) (1985) 827-863.

[6] J. Israelachvili, Intermolecular and Surface Forces, Academic Press, New York, 2004. 
[7] R. Mohammadi, W.H. Finlay, W. Roa, A. Amirfazli, Determination of Contact Angle Microspheres by Microscopy Methods, Proceedings of the International Conference on MEMS, NANO and Smart Systems, 2003.

[8] J. Glodek, P. Milka, I. Krest, M. Keusgen, Sens Actuators B 83 (426) (2002) 82-89.

[9] J. Chakraborty, S. D. Sarkar, S. Chatterjee, M. K. Sinha, D. Basu, Colloids and Surfaces B: Biointerfaces 66 (2) (2008) 295-298.

[10] C. Erisken, D. M. Kalyon, H. Wang, Biomaterials 29 (30) (2008) 4065-4073.

[11] S. Gao, Y. Wang, T. Wang, G. Luo, Y. Dai, Bioresource Technology (2008) doi:10.1016/j.biortech.2008.06.060.

[12] L. F. Zhang, R. Sun, L. Xu, J. Du, Z. C. Xiong, H. C. Chen, C. D. Xiong, Materials Science and Engineering: C 28 (1) (2008) 141-149.

[13] L. Safinia, N. Datan, M. Höhse, A. Mantalaris, A. Bismarck, Biomaterials 26 (36) (2005) 7537-7547.

[14] M.T. Khorasani, H. Mirzadeh, Z. Kermani, Applied Surface Science 242 (3-4) (2005) 339-345.

[15] T. Białopiotrowicz, B. Jańczuk, Applied Surface Science 201 (1-4) (2002) 146-153. [16] W. Prissanaroon, N. Brack, P. J. Pigram. P. Hale, P. Kappen, J. Liesegang, Synth Met 154 (2005) 105-108.

[17] V. N. Vasilets, G. Hermel, U. Konig, C. Wener, M. Muller, F. Simon, et. al., Biomaterials 18 (1997) 1139-1145.

[18] J. M. Li, M. J. Singh, P. R. Nelson, C. M. Hendricks, M. Itani, M. J. Rohrer, et. al, J Surg Res 105 (2002) 200-208. 
[19] M. Crombez, P. Chevallier, R. C. Gaudreault, E. Petitclerc, D. Mantovani, G. Laroche, Biomaterials 26 (2005)1402-1409.

[20] P. Chevallier, R. Janvier, D. Mantovani, G. Laroche, Macromol Bio Sci 5 (2005) 829-839.

[21] E. T. Kang, K. L. tan, K. Kato, Y. Uyama, Y. Ikada, Macromolecules 29 (1996) 6872-6879.

[22] R. K. Y. Fu, Y. F. Mei, G. J. Wan, G. G. Siu, P. K. Chu, Y. X. Huang, X. B. Tian, S. Q. Yang and J. Y. Chen, Surface Science 573 (3) (2004) 426-432.

[23] H. Y. Kwong, M.H. Wonga, Y.W. Wong, Appl. Surf. Sci. 253 (22) (2007) 88418845.

[24] G. Q. Blantocas, H. J. Ramos and M. Wada, Rev. of Sci. Instru. 75 (9) (2004) 28482853.

[25] G. Q. Blantocas, H. J. Ramos, M. Wada, Jpn. J. Appl. Phys., 45 (10B) (2006) 85258530

[26] J.M. Goddard, J.H. Hotchkiss, Prog. Polym. Sci. 32 (2007) 698-725.

[27] S. Guruvenket, M. Kumath, S. P. Vijayalakshmi, A. M. Raichur and G. M. Rao: J. Appl. Polym. Sci. 90 (2003) 1618

[28] G. S. Tzeng, H. J. Chen, Y. Y. Wang, C. C. Wan, Surf. and Coatings Technol. 89 (1997) 108-113. [38] D. W. Dwight, W. M. Riggs, J Colloid Interface Sci 48 (1974) 650. [29] F. Garbassi, M. Morra, E. Occhiello, Chapter 4, Polymer Surfaces: From Physics to Technology, Wiley: New York, 1994. 
[30] G. Q. Blantocas , P. E. R. Mateum, R. W. M. Orille, R. J. U. Ramos, J. L. C. Monasterial, H. J. Ramos, L. M.T. Bo-ot, Nucl. Instru. and Meth. in Phys. Res. B 259 (2) (2007) 875-883.

[31] F. Wooten, Optical Properties of Solids, Academic Press, New York, 1972.

\section{FIGURE CAPTIONS}

Figure 1: Illustrations of the experimental setup. (a) Schematic diagram of the overall facility. (b) Schematic diagram of the GDIS.

Figure 2: (a) Typical mass spectra of LEHIS at varied plasma discharge currents. (b) Plot of the ion flux density at different discharge conditions.

Figure 3: Typical numerical constructs of Eq. 3 (wetting model) fitted against the temporal recession of the contact angles for all PTFE samples.

Figure 4: (a) SEM image of a representative sample from the control group, (b) typical SEM image from the group processed at low discharge currents, $\mathrm{I}_{\mathrm{d}}=1.0 \mathrm{~mA}$, (c) typical SEM image from the group processed at $\mathrm{I}_{\mathrm{d}}=2 \mathrm{~mA}$, and (d) typical SEM image from the group processed at higher discharge currents, $\mathrm{I}_{\mathrm{d}}=3 \mathrm{~mA}$.

\section{TABLE CAPTIONS}

Table 1: Summary of experimental parameters.

Table 2: Relationship of discharge current, optical transmittance, and index of refraction. 


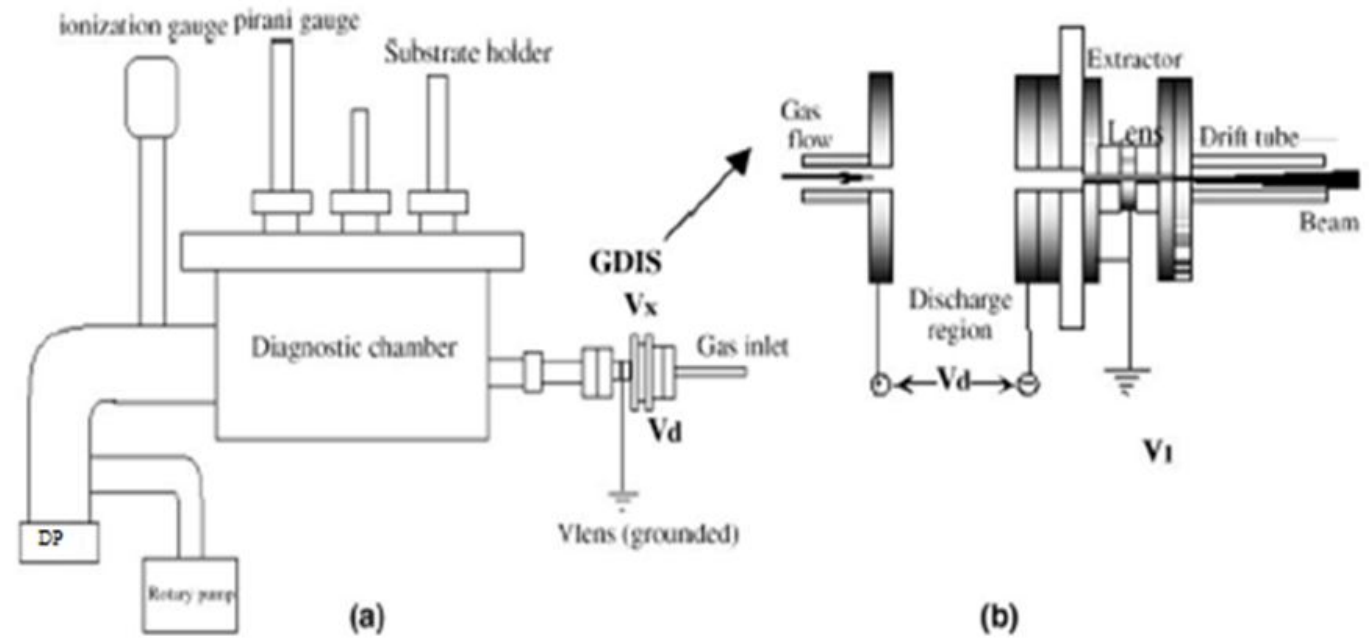

Figure 1: Illustrations of the experimental setup. (a) Schematic diagram of the overall facility. (b) Schematic diagram of the GDIS. 


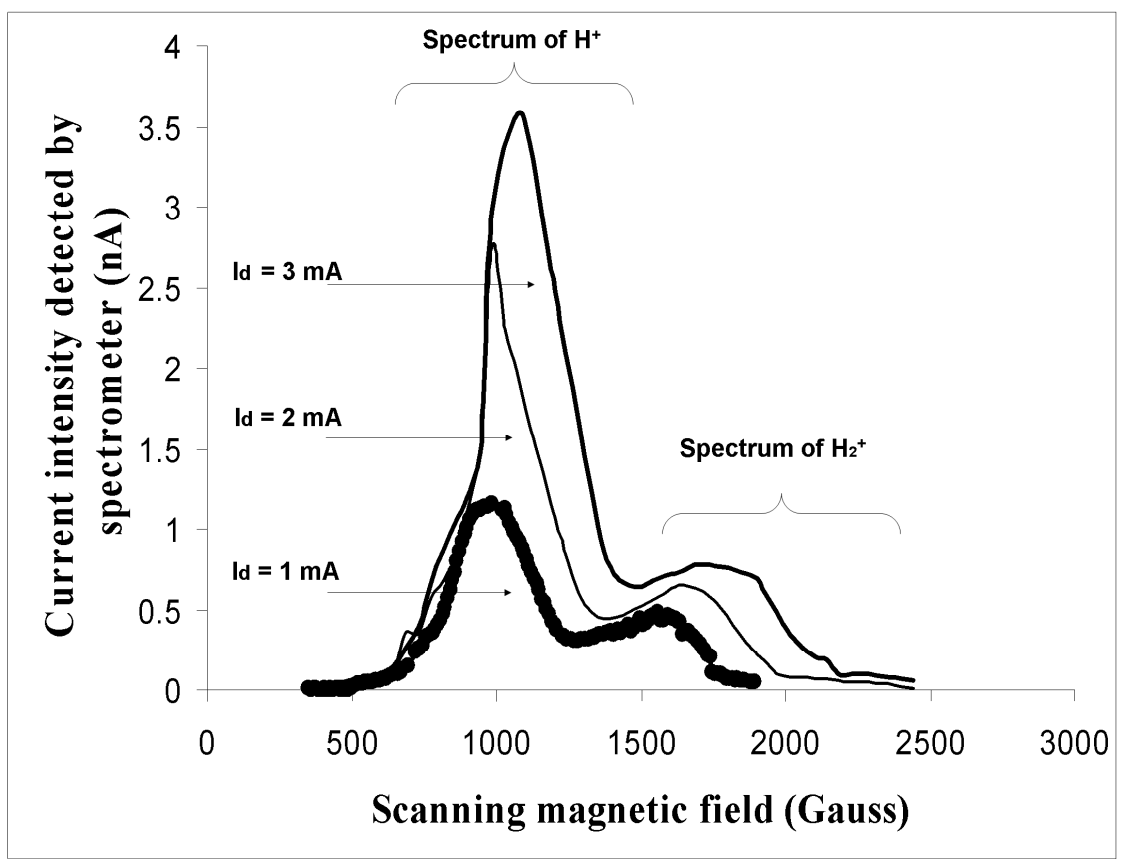

(a)

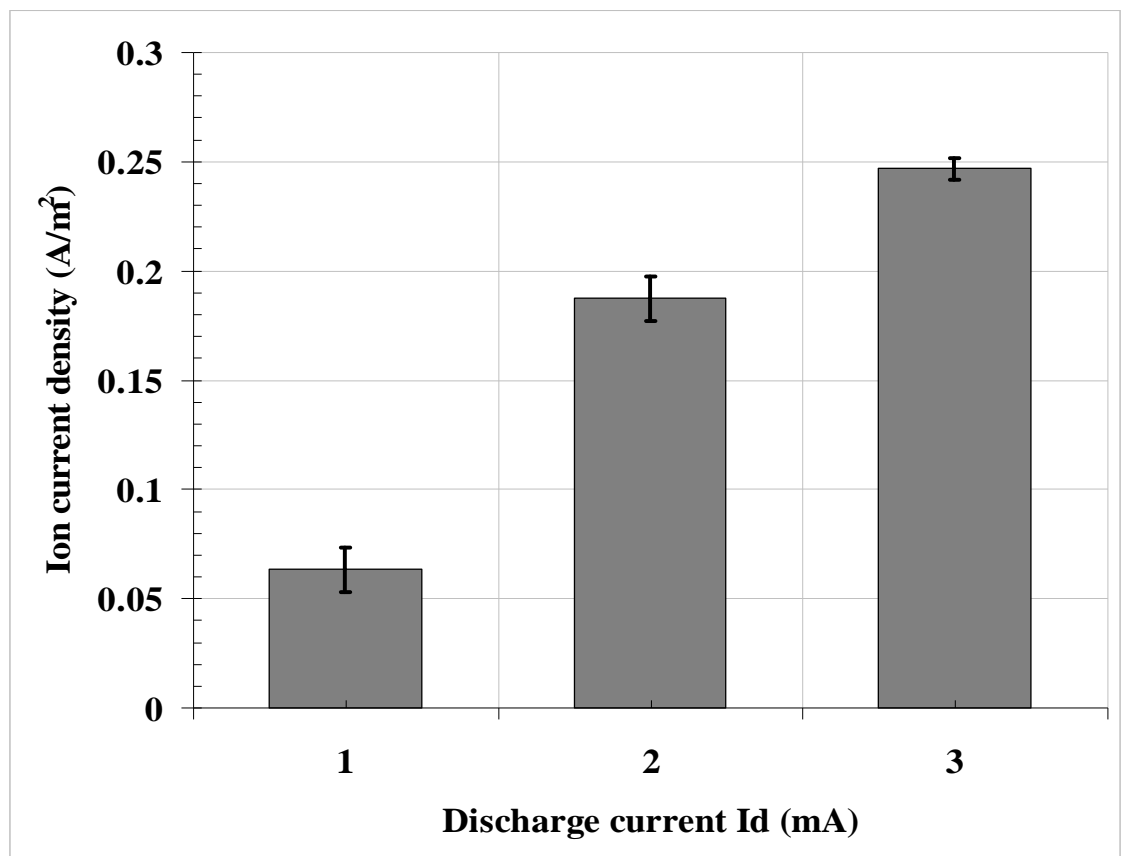

(b)

Figure 2: (a) Typical mass spectra of LEHIS at varied plasma discharge currents. (b) Plot of the ion flux density at different discharge conditions. 


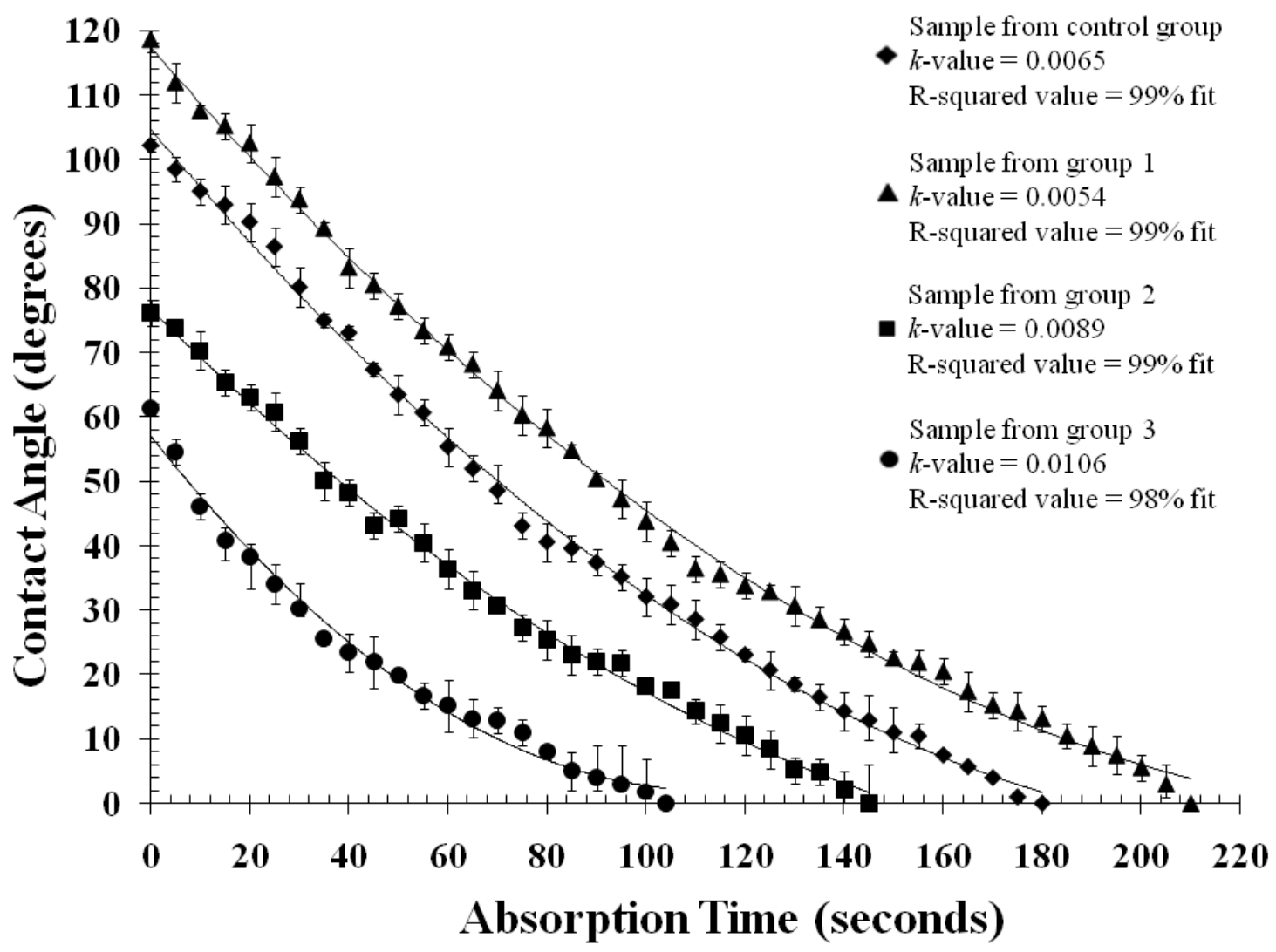

Figure 3: Typical numerical constructs of Eq. 3 (wetting model) fitted against the temporal recession of the contact angles for all PTFE samples. 


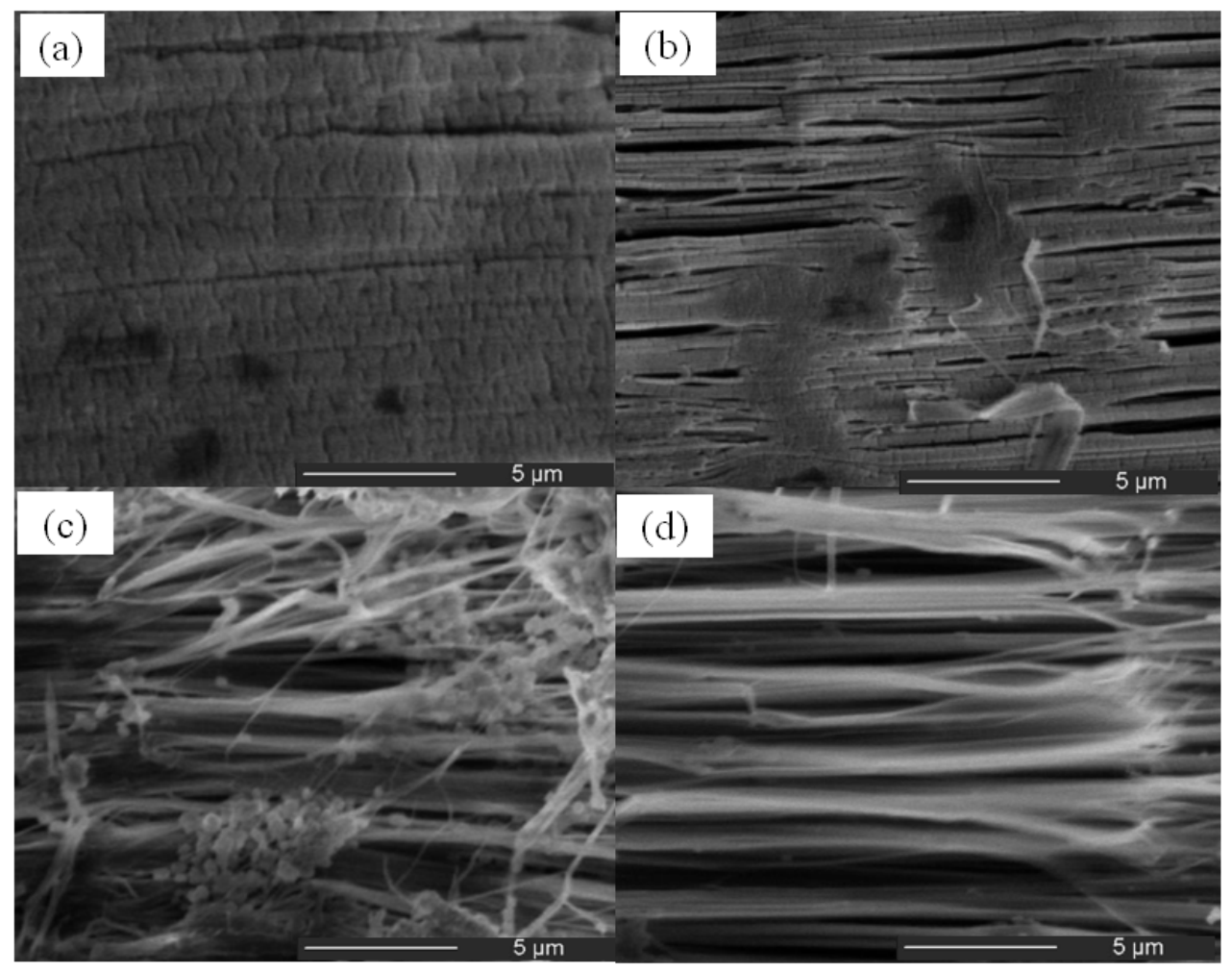

Figure 4: (a) SEM image of a representative sample from the control group, (b) typical SEM image from the group processed at low discharge currents, $\mathrm{I}_{\mathrm{d}}=1.0 \mathrm{~mA}$, (c) typical SEM image from the group processed at $\mathrm{I}_{\mathrm{d}}=2 \mathrm{~mA}$, and (d) typical SEM image from the group processed at higher discharge currents, $\mathrm{I}_{\mathrm{d}}=3 \mathrm{~mA}$. 
Table 1: Summary of experimental parameters.

\begin{tabular}{cccc}
\hline $\begin{array}{c}\text { Treated } \\
\text { Group }\end{array}$ & $\begin{array}{c}\text { Irradiation } \\
\text { Time } \\
(\text { mins })\end{array}$ & $\begin{array}{c}\text { Discharge } \\
\text { Voltage, } \\
\mathrm{V}_{\mathrm{d}} \\
(\mathrm{kV})\end{array}$ & $\begin{array}{c}\text { Discharge } \\
\text { Current } \\
\mathrm{Id} \\
(\mathrm{mA})\end{array}$ \\
\hline 1 & 30 & 1.0 & 1.0 \\
2 & 30 & 1.3 & 2.0 \\
3 & 30 & 1.4 & 3.0 \\
\hline
\end{tabular}

Table 2: Relationship of discharge current, optical transmittance, and index of refraction.

\begin{tabular}{cccc}
\hline Group & $\begin{array}{c}\text { Discharge } \\
\text { current, Id } \\
(\mathrm{mA})\end{array}$ & $\begin{array}{c}\text { Optical } \\
\text { transmittance } \\
(\%)\end{array}$ & $\begin{array}{c}\text { Index of } \\
\text { refraction }\end{array}$ \\
\hline Control & 1 & 82.56 & 1.19 \\
1 & 2 & 69.12 & 1.22 \\
2 & 3 & 95.93 & 1.10 \\
3 & & 98.34 & 1.07 \\
\hline
\end{tabular}

